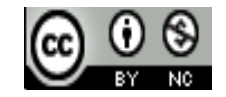

Jurnal Pendidikan Matematika Indonesia is licensed under

A Creative Commons Attribution-Non Commercial 4.0 International License

\title{
Mathematical Difficulties Learners in Solving Creative THINKING IN THE GEOMETRY ABILITY
}

\author{
Depi Setialesmana ${ }^{1)}$ \\ 1) Mathematics Educational Courses, FKIP Siliwangi, University in Tasikmalaya \\ E-mail:depi_setia23@yahoo.co.id
}

\begin{abstract}
The purpose of this study to identify the Difficulties and disadvantages experience by learners in terms of the process of settlement problems of mathematical creative thinking abilities part of indicators. The research instrument used was a matter of mathematics creative thinking ability test and interview guidelines Subject in this study in class VIII-D Junior High School. Based on the research results, Difficulties and disadvantages experienced by learners when solving test creative thinking abilities mathematics include, most learners do not express a variety of ideas, ideas or plans of settlement diverse, does not solve the problem in various ways, does not try to solve problems in ways own or use a non-standard way, and most learners do not develop and elaborate the answer in solving problems.
\end{abstract}

Keywords: Difficulties, Creative Thinking

\section{INTRODUCTION}

Skills to think or thought that trained not only important in the world of work, education and research or research. These skills are essential to be owned by everyone both in the workplace and in everyday life. This is similar to the phrase that was brought by Sudarma, Momon (2013: 34) states "With its good thinking skills, someone will have the capital to be able to solve the problem that happened in his life".

The skills need to be developed in the mathematical sciences are skills in creative thinking skills so that learners can further develop its mathematical abilities. Based on research in SMP Negeri 4 Tasikmalaya has been done by Mazhardy, Rifki Ramdhan (2013) concerning the ability of creative thinking mathematically, the data obtained from the results of his research after the data created in the five-point scale is the largest percentage is in the interval $11 \leqslant \mathrm{C}<15$ $60 \%$ learners with a level of mastery of the material classified as moderate. While there is the lowest frequency in the interval score $18 \leqslant \mathrm{~A} \leqslant 20$ that only $7.5 \%$ of students with an excellent level of mastery of the material.

This shows that not all learners have the ability to think creatively higher mathematics, the data that exist on the criteria most moderate and the least data exist on the criteria very well. In addition, learners who reached KKM as many as 11 people with $27.5 \%$ and the percentage of learners who have not yet reached KKM as many as 29 people with a percentage of $72.5 \%$.

Subsequent research conducted in MTs Futuhiyyah 2 Mranggen the mathematical creative thinking ability that was done by Faizah, Ulfa Aminatul (2013). Research results show that creative thinking pattern of 20 learners as much as $10.26 \%$ of high category, the category was as much as $38.46 \%$, and as much as $51.28 \%$ lower categories. From the results of this study indicate that the mathematical creative thinking abilities of learners is still low.

This can be caused because students find difficulty in solving problems of mathematical creative thinking ability tests. Based on research that has been done by Ratnaningsih, Nani (2007) 
that the description of the general performance of learners in solving problems are: lack of attention to the question in the matter or less careful in understanding the problem, so that learners incomplete answers; still weak in turning about the story into a mathematical model; answered about inadvertently making the wrong in the calculation; and did not re-examine what has been done.

Some The research results show that learners have a wide range of characters that is always required to develop and enhance their creativity. Process improvement and development of creativity of learners, including the development of creative thinking abilities mathematics and become familiar with them in mathematics. Mathematical creative thinking ability is the ability to develop ideas derived from the study of literature (literature) to get a new concept of science that has been obtained previously. Indicators of creative thinking that fluency (fluency), flexibility (flexibility), elaboration (breadth), Originality (authenticity).

In response to these problems, we need innovation in mathematics learning process that needs to be done by teachers especially learning model used. The learning process is innovative and creative to do the math teacher is one of them by applying the learning model Inquiry Alberta and model of Problem Based Learning (Problem Based Learning).

Learning model Inquiry Alberta will train creative thinking abilities of learners in finding concepts and principles of learning. Branch, Jennifer and Dianne Oberg (Alberta Learning, 2004: 1) states that Alberta Inquiry learning model is the "process by which learners are involved in their learning, formulate questions, investigate widely and then build a new understanding, meaning and knowledge". With the knowledge that has been owned by learners before, then the teacher will guide learners to discover the concepts and principles of mathematics material being studied. However, the guidance provided is limited and few.learning model Inquiry Albertais a process where learners are engaged in learning, formulate questions, investigate widely and then build a new understanding, meaning and knowledge. Stages inlearning model Inquiry
Alberta that is planned (planning), recall (retrieving), finishing (processing), creating/generating (creating), giving and receiving (sharing), and evaluate (evaluating).

The learning model is selected to determine the difficulty of mathematical creative thinking abilities of learners. The model also emphasizes the active learners in solving mathematical problems that are academic, to measure creative thinking abilities of each learner. The purpose of the problem to determine and medeskripsikan What difficulties experienced by learners in solving problems of mathematical creative thinking abilities and to know what is experienced shortages of learners in solving problems of mathematical creative thinking abilities of eachindicator?

\section{METHODS}

Purposively selected data source that is above considerations. The subject is the students of SMPN 1 Banjarsari with respondents VIII D were 41 learners Focus research to identify difficulties and disadvantages experienced by learners in terms of the process of settlement problems of mathematical creative thinking abilities of each indicator.

Data collection techniques used in this study, namely, Mathematics Creative Thinking Skills test and interview. Instrument of research is about the ability to think creatively mathematical and interview guidelines. The data obtained from the test results as a reference to determine the level of difficulty experienced by learners in working on these issues, and what factors cause this to happen. These tests were performed one after the learning process is carried out. Regarding the interview as well as the difficulties experienced by learners in solving problems Matematik.Wawancara Creative Thinking Ability tests used are semi-structured interviews.

To know these difficulties there are six steps that need to do is choose the students who make mistakes or errors fatal, grouping of students based on the type of fault, choose three students who make mistakes are different to each aspect of creative thinking abilities mathematics, ask 


\section{- - - Jurnal Pendidikan Matematika Indonesia \\ Volum 2 Nomor 1 bulan Maret 2017. Page 1-6 \\ p-ISSN: 2477-5967 e-ISSN: 2477-8443}

learners look back job, held a debriefing process with learners and record the results in a question and answer interview guidelines.

\section{RESULTS AND DISCUSSION}

Creative thinking ability test data obtained. For about the first measures the smoothness indicator which measures the ability of learners to provide a lot of ideas and a lot of answers to be able to give an exact answer. This problem can be solved by using the formula of the surface area of the beam, as in the matter mentioned "prism squares" so that from that learners should not be stuck with the context of the sentence in question in the matter, to determine the possibility of settlement of this problem learners have to be creative in determining the numbers precisely because the factors of numbers ending in zero can be a number multiples of 5 and 10 as well as an even number.

In this matter, there are still many students who err in answering the questions. One of the answers to the following learners.

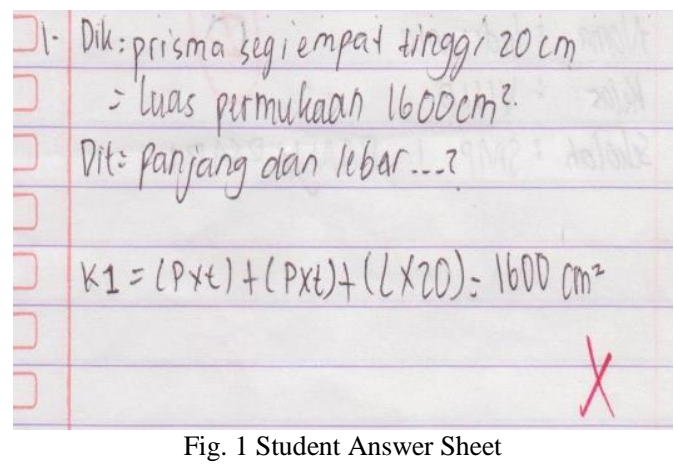

From the results of the completion of the number one, the students looked bewildered working and solving problems. How to do it was wrong because the formula used is wrong and learners tend to forget with these formulas because they do not remember and do not try to learn to work on the problems at home, so they tend to forget formulas to be used to solve the problems in the problem number one and resulted in participants learners do not know how to solve it.

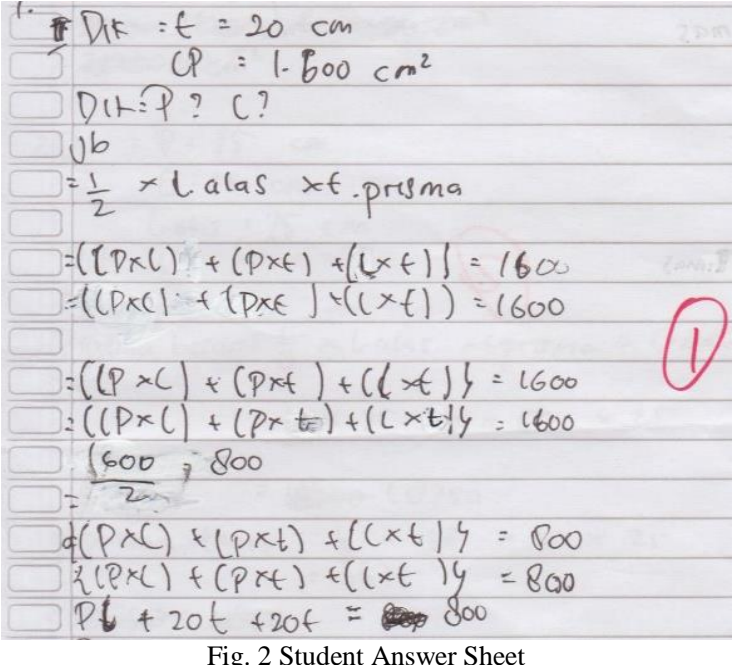

From the completion of the second question number one, seen learners already stuck with a problem, the students wrote the formula wrong prism surface area and convert it into the formula beam surface area that is also wrong. Learners also looks confused in solving because he inadvertently resolving this problem and do not know the steps in resolving this matter.

So, from some types of errors were committed learners to Question 1, it is concluded that the learners are not able to understand the material / concept with good and less practiced in working on. Most learners tend to not remember the formula and confused in resolving this problem and there are learners who are careless in working on so that learners are less careful in calculating and does not attempt to re-examine the answer.

Problem number two is to measure aspects of flexibility which measures the ability of students to solve problems in different ways and the answers varied. This problem-solving process can be done by looking at how many beams is small and there are how many pyramid. By using a formula approach the pyramid volume and the volume of the beam, then the settlement of this problem can be solved in a creative way. The beam can be seen as a big block and small block with different lengths so that there are various ways to solve them. So the size of the room got up volume is the sum of the third volume of a pyramid and the five beams that form a small or a large beam shape. 


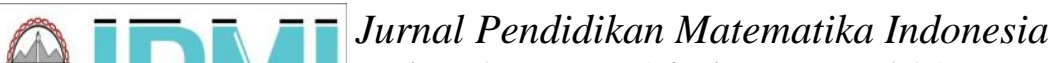 \\ Volum 2 Nomor 1 bulan Maret 2017. Page 1-6 \\ p-ISSN: 2477-5967 e-ISSN: 2477-8443}

This problem-solving process, learners are still many difficulties in doing it. As answers to these learners.

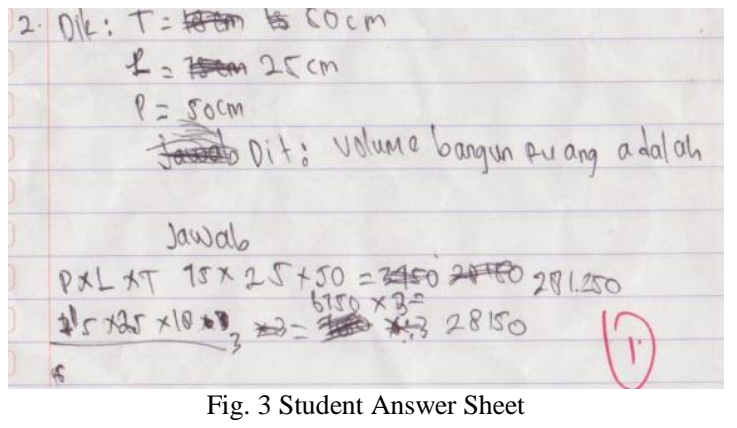

Examples of such settlement learners tend to be confused in the work on the problems. The formula learners have used are correct, but the operation is still wrong calculations done in multiplication. Learners also forget the pyramid volume formula, so that learners are only writing formula beam volume alone.

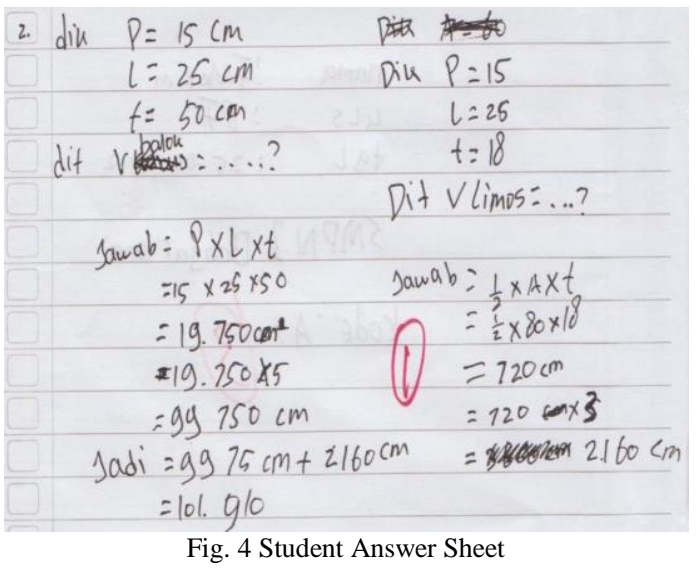

Based on the answers to such learners shows that learners are already able to understand the questions well. However, learners are still wrong in writing the pyramid volume formula. Learners simply write the formula for the area of triangle is not a pyramid volume formula to determine the volume of a pyramid-learners still wrong. Then the process of calculating the volume of the beam is still wrong, learners are less cautious in doing multiplication operation in the search for the beam volume so the results are wrong.

So, from some of the problem-solving can be concluded that the learners are still many who do not understand and know the material well, especially in the application of the formula of the matter, then there are still many who do wrong calculation process and forget to remember the formula. In addition, there are also students who have been working on the questions well, but he lacks understanding and look about so that what is being asked and asked the question was not answered perfectly by the learners so that learners are still sloppy and less cautious in working on and not trying to check back the answer.

Problem number three is to measure aspects of the authenticity of the ability of learners to provide the concept and answers with the language and its own way. On this matter, learners do not be fooled by the problems presented in the matter, to answer the broad mica thick takes a lot of students who are still fooled when using broad approach of the pyramid can be obtained broad mica thick needed but the broad base of zero because the pyramid of the shaped hood of food. As for the wide table can be covered with the hood of food, learners must use the Pythagorean proposition approach in completing and using the formula for the area of the triangle. But to know this, learners must use creative thinking to see the possibility of the process being performed.

There are several answers learners interesting to discuss because there are errors that learners do in solving problems such as the following three numbers.

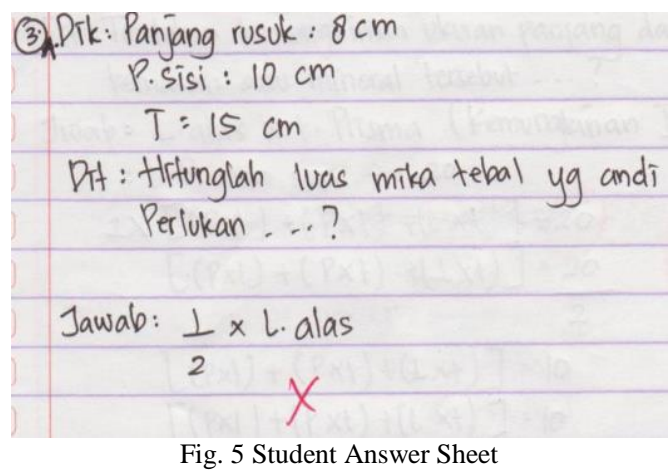

Based on the answers from learners shows that the learners are not able to work on the problems. Learners forget a formula to do it and do not know how to do it so that learners do not resolve the problem. In addition, learners also when interviewed do not remember the formula for the area of triangle and the Pythagorean proposition so that learners do not know how to do the problems 
in his own way. In this case the learners must often practice and learn that things like this can be minimized.

Answer learner shows that learners do not understand the Pythagorean proposition. Indeed, learners are already looking at the questions well because the answer to $3 \mathrm{a}$ are correct and they are not fooled.

So, from some of the answers that learners can be concluded that the students did not master the material well. The material must be mastered not only the material woke up this space alone, but must connect between this material with material that has been studied before, because at this Question 3 learners have to work accurately with the knowledge and the level of his own creativity. Most learners can do about this properly, no one answered because with less caution and careless, so not in accordance with the demands of questions being asked, the students also tend to forget again with the concept of the arguments of Pythagoras and the formula for the area of the triangle, so the majority of learners can not answer the question carefully and precisely. In addition, the students also find it difficult to change the shape of non-routine matter in the form of a mathematical model that most learners who are fooled and answer because wrong because they do not know the concept and do not understand the material very well.

Problem number four in measuring the breadth of that measure the ability to develop answers or knowledge given to explain, or describe in more detail enriching the knowledge. On this question, the learner must be creative in solving because, the higher the size of the rest of the prism should be known in advance by multiplying the volume of the rest of the glass with a tall glass. Then the number of ice cubes to be incorporated into the glass makes the water glass rises following the shape of the prism so that the volume equal to the volume of a prism with a height of water is spilled. Then after the calculation process will be obtained high-water spill. Due to the high residual value that is smaller than the height of high water spilled spilling excess water will be obtained by reducing the water level with a high residual spill. Thus, the volume of water that would spill can be determined by using a prism volume formula.

There was some confusion and mistakes of the answers learners will be described below.

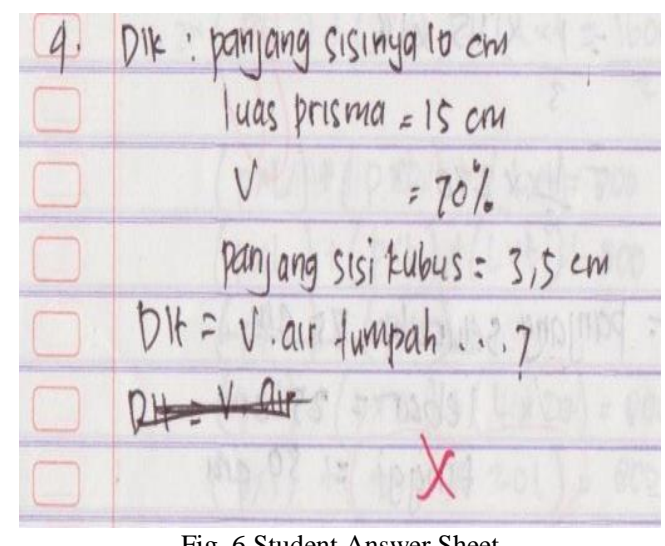

The answer from the students indicates that learners do not understand the material very well, so confused about how to do it. Learners also do not remember the formula and do not know how to do it.

So, from a few answers to such learners can be deduced that learners do not understand the concept and the material well. Learners do not practice work on the problems at home and learners are less careful in performing the calculation process. Learners do not know how to do it even while learning already discussed together. Learners tend to forget formulas and careless in the application of the formula. They are wrong in writing a symbol of multiplication and addition. Learners are also likely not trying to reexamine their work so that mistakes and errors that do not unanalyzed and not corrected for the reason pursuit time to work on the problems others.

\section{CONCLUSION}

In conclusion difficulties experienced by learners when solving mathematical creative thinking ability tests include, most learners do not put forward various ideas, ideas or diverse settlement plan, does not solve the problem in different ways, do not try to solve problems in ways own or use a non-standard way, and most learners do not develop and itemize the answer in solving the problem. Shortcomings in the 
performance of students in general in solving problems are: lack of attention to the question in the matter or less careful in understanding the problem, so that students are less complete answer; still weak in turning about the story into a mathematical model; answered about inadvertently making the wrong calculation. Her advice Learners are expected to improve the ability to think creatively mathematical manner diligent study, understand the material well and often practice in working and completing math problems so that the process of thinking learners can grow and develop into a better direction.

\section{REFERENCES}

Alberta Learning. (2004). Focus on Inquiry: A Teacher's Guide to Implementing InquiryBasedLearning:Canada: Learning Resources Center.

Faizah, Ulfa Aminatul. (2013). Mathematical Analysis of Creative Thinking Ability of Students at MTs Futuhiyyah 2 Mranggen through the administration of the Open-EndedQuestions.Thesis IAIN Walisongo. Semarang: Unpublished

Mazhardy, Rifki Ramdhan. (2013). Influence of Cooperative Learning Model Student Facilitator and Explaining on Mathematics Creative Thinking Ability ofStudents.Thesis UNSIL. Tasikmalaya: Unpublished.

Ratnaningsih, Nani. (2007). Effect of Contextual Learning to Critical and Creative Thinking Skills Mathematics and Learning Independence High SchoolStudents.Dissertation UPI. Bandung: Unpublished.

Sudarma, Momon. (2013). Developing Creative ThinkingSkills.Jakarta: PT. RajaGrafindo Persada. 